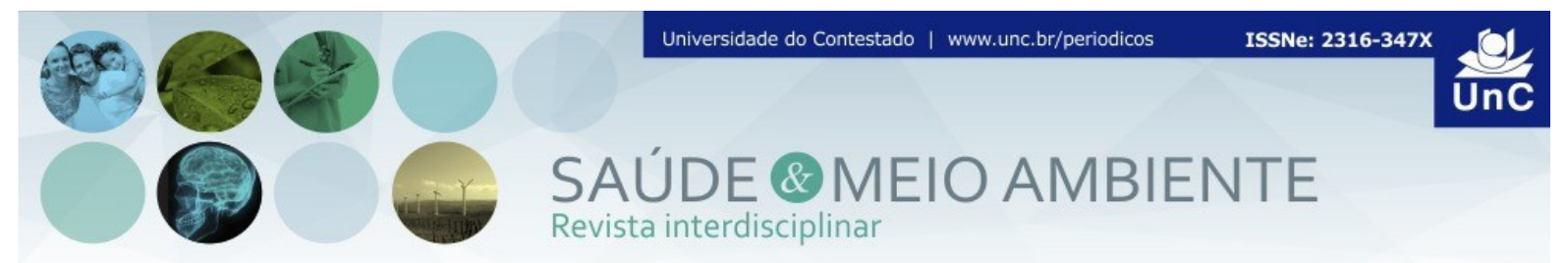

\title{
VIGILÂNCIA AMBIENTAL DO VÍRUS DA HEPATITE NA CIDADE DE SÃO PAULO, BRASIL
}

\author{
Tatiana Prado ${ }^{1}$ \\ Mikaela Renata Funada Barbosa² \\ Suzi Cristina Garcia ${ }^{3}$ \\ Maria Inês Zanoli Sato ${ }^{4}$
}

\begin{abstract}
RESUMO
O vírus da hepatite $E$ (HEV) é um agente emergente causador de hepatite entérica aguda em diversas regiões do mundo. No Brasil, taxas de soro-prevalência têm sido determinadas em $6 \%$ na população adulta e em $3 \%$ na população geral, evidenciando que a hepatite $E$ no Brasil não é rara. Entretanto, a epidemiologia geral do vírus ainda é pouco estudada no país e não temos dados abrangentes de monitoramento ambiental. O objetivo desse estudo foi monitorar o HEV em amostras de esgoto bruto, efluentes secundários e água de reúso na região metropolitana da cidade de São Paulo, Brasil, durante o período de um ano (abril de 2015 a março de 2016). Amostras foram coletadas mensalmente em 4 grandes Estações de Tratamento de Esgotos (ETEs), responsáveis pelo tratamento de esgotos de uma população equivalente a 8 milhões de pessoas residentes na cidade. Genomas virais foram investigados através de reação em cadeia da polimerase quantitativa (qPCR). Genomas de HEV não foram detectados durante todo o programa de monitoramento. Embora os resultados sugerem que a taxa relativa de circulação do vírus no ambiente pesquisado é baixa, os desafios analíticos relacionados aos limites dos métodos moleculares utilizados para detectar genomas virais em amostras ambientais são discutidos. Essa foi a primeira iniciativa para obter dados de HEV circulantes em matrizes ambientais na cidade de São Paulo e espera-se que futuros estudos de vigilância ambiental sejam conduzidos, apoiando políticas públicas mais efetivas de controle ambiental e prevenção da saúde com relação às doenças virais de veiculação hídrica.
\end{abstract}

Palavras-chave: Doenças de veiculação hídrica. Saneamento. Saúde pública. Vigilância ambiental.

\footnotetext{
${ }^{1}$ Doutora em Ciências pelo Instituto Oswaldo Cruz - Fundação Oswaldo Cruz (IOC/FIOCRUZ/RJ). Mestre em saúde pública com ênfase em Saneamento e Saúde Ambiental pela Escola Nacional de Saúde Pública (ENSP/FIOCRUZ/RJ) e Graduada em ciências biológicas pela Universidade Estadual de Campinas (UNICAMP/SP). Companhia Ambiental do Estado de São Paulo (CETESB). São Paulo. Brasil. E-mail: tatianaprado436@gmail.com

${ }^{2}$ Mestre em Epidemiologia Experimental e Aplicada às Zoonoses. Universidade de São Paulo (USP). Gerente da Divisão de Microbiologia e Parasitologia da Companhia Ambiental do Estado de São Paulo (CETESB). Companhia Ambiental do Estado de São Paulo (CETESB). São Paulo. Brasil. E-mail: mrbarbosa@sp.gov.br

${ }^{3}$ Bacharel em Ciências Biológicas pela Universidade de Mogi das Cruzes (UMC) e virologista da Companhia Ambiental do Estado de São Paulo (CETESB). Companhia Ambiental do Estado de São Paulo (CETESB). São Paulo. Brasil. E-mail: scgarcia@sp.gov.br

${ }^{4}$ Doutora em Ciências (Microbiologia) pela Universidade de São Paulo (USP). Gerente do Departamento de Análises Ambientais, da Companhia Ambiental do Estado de São Paulo (CETESB). Companhia Ambiental do Estado de São Paulo (CETESB). São Paulo. Brasil. E-mail: misato@sp.gov.br
} 


\title{
ENVIRONMENTAL SURVEILLANCE OF HEPATITIS E VIRUSES IN SÃO PAULO CITY, BRAZIL
}

\begin{abstract}
The hepatitis $E$ virus (HEV) is an emergent causative agent of enteric acute hepatitis worldwide. Seroprevalence has been determined in $6 \%$ in the adult population and in $3 \%$ in the general population, evidencing that hepatitis $E$ is not uncommon in Brazil. However, the overall epidemiology of the virus is still poorly studied in the country and we do not have comprehensive environmental monitoring data. The aim of this study was monitor HEV in urban sewage, secondary effluents and reclaimed water from metropolitan São Paulo, Brazil, during one-year period (April 2015 to March 2016). Samples were collected monthly in four large wastewater treatment plants (WWTPs), responsible for treating sewage from a population equivalent to 8 million people living in the city. Viral genomes were investigated through quantitative polymerase chain reaction (qPCR). HEV genomes were not detected during all monitoring program. Although the results suggest that there is a relatively low rate of virus circulation in the studied environment, analytical challenges related to the limits of the molecular methods used to detect viral genomes in environmental samples are discussed. In any case, this was the first initiative to obtain HEV monitoring data in environmental matrices in the São Paulo city and it is expected that future environmental surveillance studies will be conducted, supporting more effective public policies for environmental control and health prevention related to viral waterborne diseases.
\end{abstract}

Keywords: Environmental surveillance. Public health. Sanitation. Waterborne diseases.

\section{INTRODUÇÃO}

$\mathrm{O}$ vírus da hepatite $\mathrm{E}$ (HEV) é um agente emergente causador de hepatite entérica aguda em todo o mundo ${ }^{1,2}$. É estimado que 20 milhões de infecções e 3,3 milhões de casos sintomáticos de hepatite $\mathrm{E}$ ocorrem anualmente ao redor do mundo, com uma estimativa de 56.600 mortes $^{3}$. Na América do Sul a epidemiologia geral tem sido pouco estudada e a carga da doença é, em muitas localidades, desconhecida ${ }^{2}$. O vírus é transmitido principalmente pela rota fecal-oral através da ingestão de água ou alimentos contaminados, embora a transmissão sanguínea também tem sido descrita ${ }^{1}$.

Surtos da doença frequentemente ocorrem em países com acesso limitado à água potável, saneamento, higiene e serviços básicos de saúde ${ }^{4}$. Em anos recentes, alguns surtos têm ocorrido em áreas de conflito humanitário, tais como zonas de guerras e campos de refugiados e vários surtos têm sido relacionados com enchentes seguidas de chuvas fortes, embora alguns surtos também têm sido descritos nas estações secas, possivelmente relacionados à maior concentração de contaminantes em cursos d'água com vazão de água reduzida ${ }^{3}$. 
Durante o verão na cidade de São Paulo há um aumento significativo dos índices pluviométricos que acarretam, com frequência, enchentes localizadas. Essas enchentes expõem potencialmente a população às doenças transmitidas pela ingestão de água contaminada. O aumento dos casos de leptospirose e, sobretudo, de hepatite $A$ após enchentes, é uma realidade na cidade de São Paulo ${ }^{5}$. Entretanto, pouco se sabe sobre a ocorrência de casos de hepatite $E$ nesse contexto. Uma possível explicação está associada ao fato da hepatite $E$ não ser uma doença de notificação compulsória, além do diagnóstico ser confundido, em muitos casos, ao da hepatite A. Como em muitas situações também não há o diagnóstico do agente etiológico responsável pelas doenças de veiculação hídrica e não há dados de monitoramento em água e esgoto, não temos informações suficientes para avaliar o impacto das infecções por HEV em situações de desastres, particularmente após enchentes.

O HEV infecta humanos e também outros animais, como veados, javalis e principalmente suínos, os quais são reservatórios desses vírus e podem ter papel importante na transmissão zoonótica ${ }^{1,2,6,7}$. Um estudo recente também identificou membros da família Hepeviridae, incluindo HEV, em amostras de sangue de roedores coletados na região nordeste do Estado de São Paulo, demonstrando que esses animais poderiam ser reservatórios importantes para manutenção do vírus no ambiente $^{8}$.

O HEV é um vírus pequeno, não envelopado (27-34 nm) com simetria icosaédria da família Hepeviridae, gênero Hepevirus ${ }^{4}$. Oito genótipos (1 a 8), com múltiplos subtipos, têm sido descritos para esse vírus, mas, somente os genótipos 1 , 2, 3, 4 e 7 são reconhecidos por infectar humanos ${ }^{2}$.

O genótipo 1 (HEV-1) e 2 (HEV-2) transmitido principalmente através da água potável contaminada têm sido detectado esporadicamente nas Américas ${ }^{2,6}$. O genótipo 3 (HEV-3) e 4 (HEV-4) são vírus zoonóticos que infectam humanos pela ingestão de alimentos contaminados, sobretudo consumo de carne mal cozida, ou contato direto com animais infectados $2,4,9$.

No Brasil, o HEV tem sido descrito recentemente entre rebanhos suínos, roedores, produtos de carne suína (patê e salsicha de sangue) e amostras ambientais $^{2,7,8,10,11}$, alertando para as possíveis rotas de disseminação do vírus no país.

A vigilância ambiental, baseada sobretudo na detecção de vírus em esgoto, é útil em rastrear patógenos virais emergentes e monitorar eventuais mudanças dos padrões epidemiológicos das doenças com rotas de transmissão fecal-oral ${ }^{4,12}$. Entretanto, pouco é conhecido sobre a circulação de HEV em matrizes ambientais, incluindo água e esgotos no Brasil, restringindo o acesso à informação sobre a prevalência e as cargas virais circulantes nestes ambientes e investigações de riscos à saúde.

Com a importância crescente dos vírus entéricos e também das viroses emergentes em surtos de veiculação hídrica em todo o mundo, a Companhia Ambiental do Estado de São Paulo (CETESB) expandiu a pesquisa desse grupo de 
patógenos, incluindo o monitoramento do vírus da hepatite $E$ em águas e esgotos para avaliar a prevalência e as cargas virais no ambiente, dando suporte ao sistema de vigilância epidemiológica e ambiental do Estado de São Paulo.

Dessa forma, o presente estudo teve como objetivo monitorar o HEV em amostras de esgotos urbanos de uma população representativa da cidade de São Paulo, efluentes secundários de Estações de Tratamento de Esgotos (ETEs) e em água de reuso produzida nessas ETEs para avaliar o potencial impacto da presença desses patógenos nessas matrizes ambientais, investigar a prevalência, distribuição e a carga viral na área amostrada.

\section{MATERIAIS E MÉTODOS}

\subsection{CARACTERÍSTICAS DAS ESTAÇÕES DE TRATAMENTO DE ESGOTOS (ETES) E AMOSTRAGEM}

São Paulo é a cidade mais populosa do Brasil, com aproximadamente 12 milhões de habitantes. Estima-se que $81 \%$ dos esgotos produzidos no município são coletados e, deste percentual, $71 \%$ são tratados ${ }^{13}$. A Região Metropolitana de São Paulo (RMSP) está dividida em duas áreas: uma, central, servida pelo Sistema Principal (ou integrado) e outra, constituída pelos municípios com sistemas próprios, ou Sistemas Isolados ${ }^{13}$. O Sistema Principal é constituído por cinco grandes sistemas de coleta, afastamento e tratamento de esgotos, dos quais 4 deles foram incluídos neste estudo por estarem em regiões estratégicas da RMSP e serem responsáveis pelo tratamento de esgotos de uma população representativa da cidade (aproximadamente 8 milhões de pessoas) (Figura 1). Estas 4 ETEs possuem vazões $\left(\mathrm{m}^{3} / \mathrm{s}\right)$ estimadas em 9,7 (ETE-1), 2,5 (ETE-2), 0,8 (ETE-3) e 1,9 (ETE-4) (Figura 1). 
Figura 1 - ETEs 1-4 localizadas na região metropolitana da cidade de São Paulo

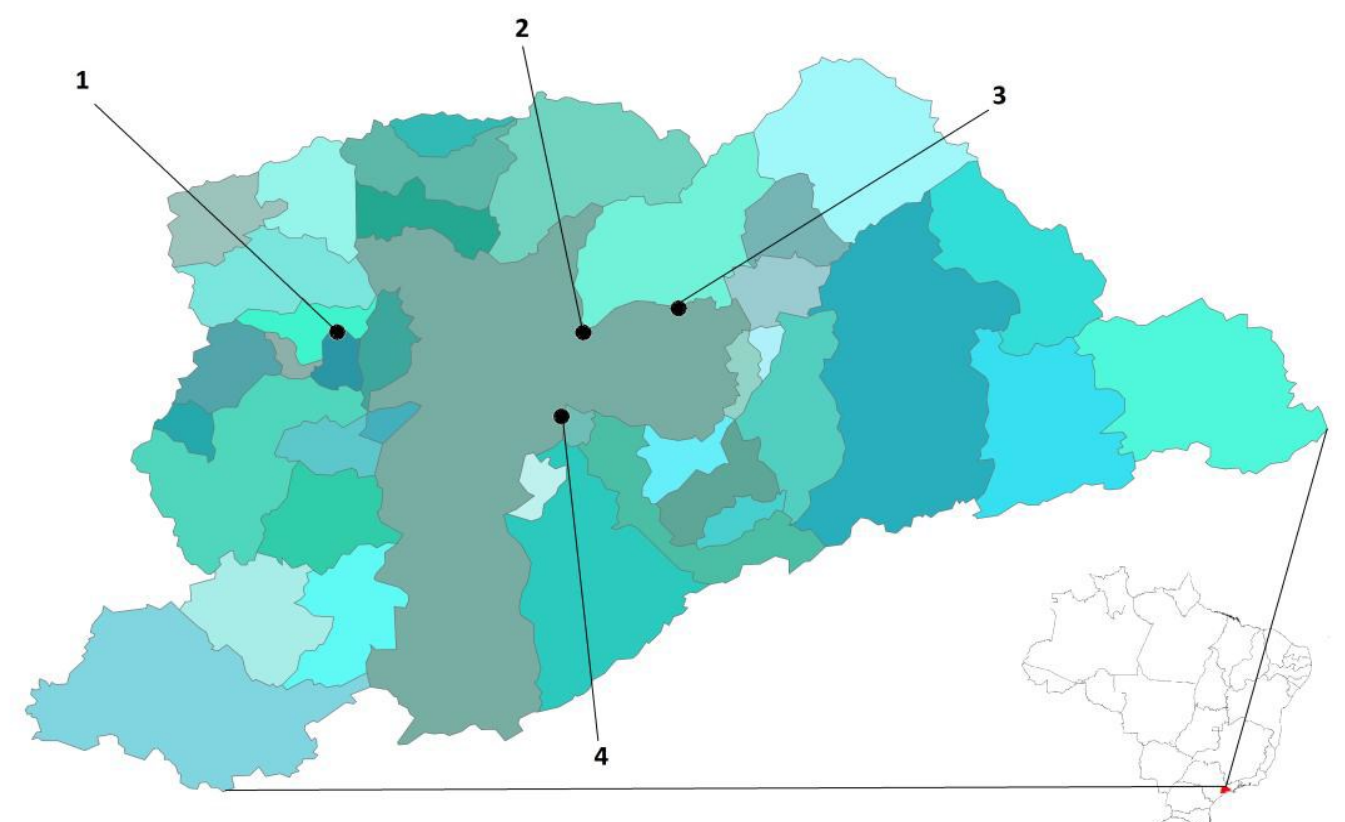

Fonte: Cetesb (2017). Mapa construído em ArcGIS. População atendida nas ETEs 1-4 (em milhões): 4,$4 ; 1,2 ; 0,72 ; 1,4$, respectivamente.

Todas as ETEs são compostas por tratamento primário, para remoção de sólidos grosseiros, tratamento biológico secundário (lodo ativado) e diferentes tratamentos terciários (filtros de areia-antracito: ETEs 1 e 3), filtro de areia antracito com adição de zeolitas precedida de coagulação, floculação e sedimentação (ETE2) e um sistema de tratamento de efluentes avançado, composto de bioreator de membrana (membrane bioreactor-MBR) (tamanho de poro: $\leq 0.05 \mu \mathrm{m}$ ) e osmose reversa (tamanho de poro: $\leq 0.001 \mu \mathrm{m})(\mathrm{ETE}-4)^{12}$. A água de reuso produzida nas ETEs é usada para propósitos não-potáveis na área urbana: irrigação de parques e jardins, lavagem de ruas e monumentos, usos industriais (pólo petroquímico), entre outros. Um volume de $500 \mathrm{~mL}$ de esgoto bruto, efluentes secundários (1L) e água de reuso $(40 \mathrm{~L}$ ) foram coletados em cada ETE mensalmente durante o período de um ano (abril de 2015 a março de 2016), totalizando 141 amostras (3 amostras de água de reuso provenientes da ETE-1 não foram fornecidas pela companhia de saneamento devido a problemas operacionais na planta). As águas de reuso foram decloradas com tiosulfato de sódio $(10 \%)$ após as coletas. As amostras foram mantidas sob refrigeração $\left(4^{\circ} \mathrm{C}\right)$ e transportadas para o laboratório para serem processadas em $24 \mathrm{~h}$. 


\subsection{CONCENTRAÇÃO VIRAL}

A concentração de vírus nas amostras de esgoto bruto e efluentes secundários foi realizada de acordo com metodologia previamente descrita por Brinkman et al. ${ }^{14}$, empregando celite (terra diatomácea). Resumidamente, extrato de carne não floculante (BD Biosciences) foi usado a 1,5\% (w/v) e misturado até o extrato de carne ser dissolvido no esgoto. Celite 577 (Sigma-Aldrich) foi adicionado a $0,1 \%(\mathrm{w} / \mathrm{v})$ e misturado até ser dispersado na amostra. $\mathrm{O} \mathrm{pH}$ foi diminuído para 4,0 $+/-0,05$, usando $\mathrm{HCl} 1 \mathrm{~N}$, por 10 min com agitação lenta, para permitir que os vírus adsorvessem ao celite. Posteriormente, as amostras foram filtradas em membrana AP20 (Millipore Corporation) por sistema a vácuo. Os vírus foram eluídos do celite com $30 \mathrm{~mL}$ de PBS 1x (sem $\mathrm{MgCL}_{2}$ e $\mathrm{CaCl}_{2}$ ), $\mathrm{pH}$ 9,0 e filtrados em membrana de poliestireno de 0,22 $\mu \mathrm{m}$, empregando o sistema Stericup/Millipore. As amostras concentradas ( $30 \mathrm{~mL}$ aproximadamente) foram estocadas a $-80^{\circ} \mathrm{C}$ até as análises posteriores.

As amostras de água de reuso (40 L) foram concentradas usando um sistema de ultrafiltração, como descrito por Smith e Hill ${ }^{15}$. Filtros de polisulfona (dialisador Fresenius Optiflux F200NR - Hemoflow) com poro de 30KDa com área superfícial de $2 \mathrm{~m}^{2}$ foram utilizados para concentração das amostras. Esses filtros foram prétratados com solução de polifosfato (NaPP) $(0,01 \%$ de NaPP em água deionizada) empregando uma taxa de circulação de $800 \mathrm{~mL} / \mathrm{min}$, aproximadamente.

Uma bomba peristáltica (Cole-Parmer Masterflex L/S - modelo 7550-30) foi usada nos experimentos e mangueiras de silicone foram acopladas ao sistema para realizar a filtração de $40 \mathrm{~L}$ de água de reuso em uma taxa de fluxo de $800 \mathrm{~mL} / \mathrm{min}$. $\mathrm{O}$ volume de água permeada foi descartada. Após a filtração, os vírus adsorvidos às fibras do filtro foram eluídos com $500 \mathrm{~mL}$ de solução de eluição (solução de retrolavagem - Tween 80 a 0,1\%, NaPP a 0,01\% e Antifoam Y-30 a 0,001\%) com o fluxo de filtração invertido para a recuperação da solução eluente (aproximadamente $500 \mathrm{~mL}$ ). Uma etapa de reconcentração dessas amostras foi realizada no intuito de diminuir o volume de concentrado final e aumentar a probabilidade de detecção viral através de métodos de biologia molecular. O método de concentração secundária foi baseado no protocolo descrito por Brinkman et al. ${ }^{14}$, como descrito anteriormente. $\mathrm{O}$ volume de concentrado final após esta etapa foi de aproximadamente $30 \mathrm{~mL}$. Após o processamento, as amostras foram estocadas a $-80^{\circ} \mathrm{C}$ para serem utilizadas nos ensaios posteriores.

\subsection{CONTROLE INTERNO}

As taxas de recuperação dos métodos usados para concentração dos vírus entéricos nas amostras de esgoto bruto, tratado e água de reuso foram avaliadas mediante o emprego de um controle viral interno (bacteriófago PP7 - ATCC 15692- 
B2) que infecta uma cepa bacteriana específica (Pseudomonas aeruginosa ATCC 15692) $)^{16}$.

As condições de crescimento da cepa hospedeira, replicação do bacteriófago PP7 e testes de recuperação foram realizadas de acordo com protocolos descritos previamente ${ }^{12,16}$. Após a replicação, o caldo nutriente contendo bacteriófagos foi filtrado (Millipore, $0,22 \mu \mathrm{m}$ ), armazenado em alíquotas de $1 \mathrm{~mL}$, as quais foram estocadas $\mathrm{a}-80^{\circ} \mathrm{C}$ até o momento de uso. Cada amostra avaliada nesse estudo ( $n$ = 141) foi inoculada com uma alíquota de PP7 (1 mL), a qual foi previamente quantificada através de PCR em tempo real ${ }^{17}$ para a determinação da quantidade de cópias de genomas de PP7 presentes antes da inoculação. Após os testes de concentração e detecção, a taxa de recuperação foi determinada de acordo com a seguinte equação:

(Eq.1) $E(\%)=$ PP7 (cópias de genoma - CG/L) após concentração / PP7 inoculado (CG) $\times 100$

\subsection{EXTRAÇÃO DE ÁCIDOS NUCLÉICOS E REAÇÃO DE TRANSCRIÇÃO REVERSA}

Para a extração do genoma viral foi utilizado o kit comercial QIAmp Viral RNA Mini Kit® (QIAGEN Sciences, Maryland, EUA) conforme as recomendações do fabricante. A síntese do DNA complementar (cDNA) foi realizada através de transcrição reversa utilizando um primer randômico (PdN6; 50A260 units; Amersham Biosciences, Chalfont St Giles, Buckinghamshire, UK) e com a enzima SuperscriptTM III Reverse Transcriptase (Invitrogen ${ }^{\mathrm{TM}}$, CA, USA), de acordo com as recomendações dos fabricantes.

\subsection{DETECÇÃO E QUANTIFICAÇÃO DOS GENOMAS VIRAIS}

A detecção e quantificação dos genomas virais foram realizadas pelo método de de reação de amplificação enzimática (Polymerase Chain Reaction - PCR) quantitativa (Real-time PCR - qPCR) utilizando sondas do sistema TaqMan e primers previamente descritos ${ }^{18}$. As reações foram corridas sob as seguintes condições: incubação a $50^{\circ} \mathrm{C}$ por 2 min para ativação da uracil-N-glycosylase, desnaturação inicial a $95^{\circ} \mathrm{C}$ por 10 min e 45 ciclos de 15 seg a $95^{\circ} \mathrm{C}$, seguido por 1 min a $60^{\circ} \mathrm{C}$.

Oligonucleotídeos de DNA sintéticos (gBlock® Gene Fragment), comercializados pela Integrated DNA Technologies (IDT, Lowa, USA), foram usados para construir a curva padrão. O tamanho dos oligonucleotídeos corresponderam a 300 pares de bases (pb), com alvo na região da ORF-3 (open reading frame) do genoma: posição de nucleotídeos 5161 a 5460 - cepa de referência M73218 
(número de acesso no GenBank). Diluições seriadas (10x) de gBlock® foram usadas para construir as curvas padrões, alcançando $10^{8}-10^{0} \log _{10}$ cópias por reação em cada ciclo de amplificação (CycleThreshold - Ct). Uma curva padrão foi gerada por regressão linear da relação entre o valor do ciclo de amplificação e número de cópias de oligonucleotídeos. Todas as reações apresentaram um coeficiente de correlação linear $\left(R^{2}\right)$ acima de 0,99 e eficiências de 96,1 ( \pm desvio padrão 2,71$)(n=$ 7). A estatística descritiva envolvendo o cálculo das correlações lineares é apresentado na Figura 2.

Figura 2 - Estatística descritiva para as curvas padrões de HEV ( $n=7$ reações de qPCR)

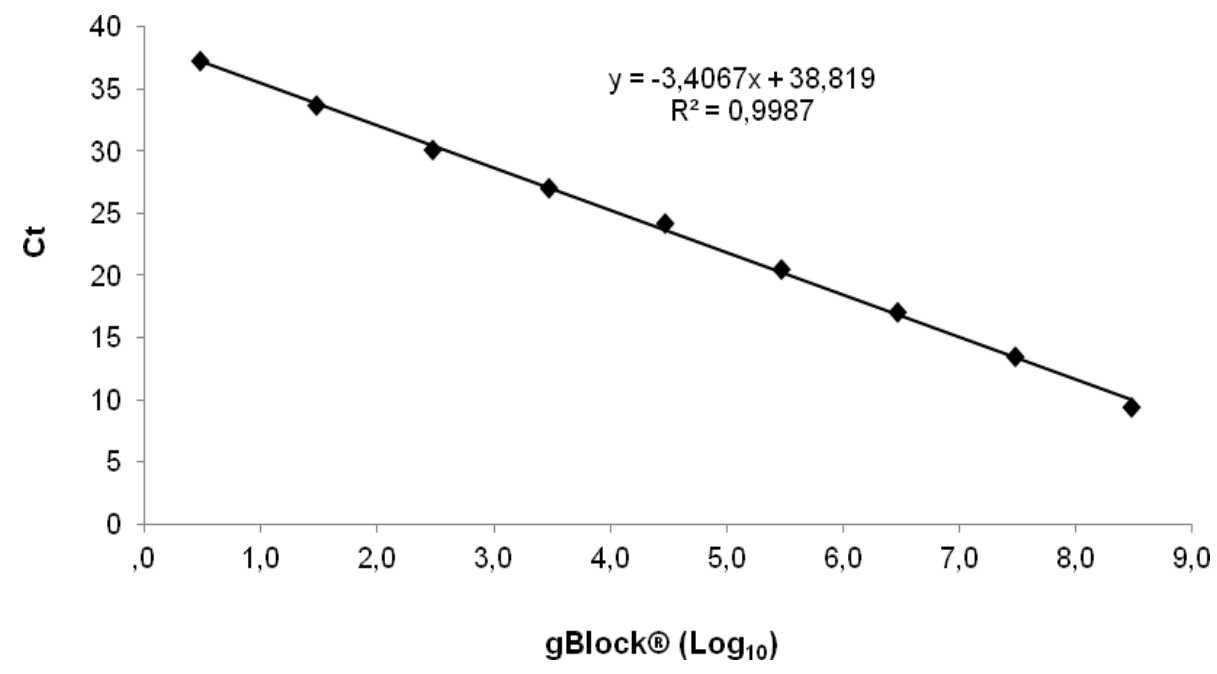

O limite de quantificação foi 5,0 cópias de genoma (CG) por $\mu \mathrm{L}$ de reação, como a mais baixa diluição padrão dentro do alcance linear da curva padrão (Figura 2). Controles positivos incluídos nas análises (HEV genótipo 3b) foram gentilmente fornecidos pelo Dr. Marcelo Alves Pinto do Laboratório de Desenvolvimento Tecnológico em Virologia, da Fundação Oswaldo Cruz - FIOCRUZ, do Rio de Janeiro. Todas as reações de amplificação (amostras, controles positivos e negativos) foram realizadas em duplicata. Os resultados foram expressos como cópias de genoma por mililitro $(\mathrm{CG} / \mathrm{mL})$, considerando os volumes de amostra, os volumes dos eluatos (amostras concentradas) $(30 \mathrm{~mL})$, os volumes de RNA extraídos e aqueles utilizados nas reações de qPCR.

\section{RESULTADOS E DISCUSSÃO}

Para esse estudo foram escolhidos dois métodos para concentrar partículas virais em esgoto bruto, secundário e água de reuso, baseados na adsorção das partículas virais ao celite (terra diatomácea) e ultrafiltração. Essa escolha foi baseada nas eficiências de recuperação e reprodutibilidade laboratorial descritas em 
estudos anteriores para detecção viral utilizando métodos de biologia molecular 14,15 e também em resultados de pré-testes que foram realizados em nosso laboratório, onde vários métodos foram comparados para recuperação viral nas respectivas matrizes ambientais.

Com base em estudos recentes e também na metodologia clássica de concentração viral, utilizando extrato de carne para recuperar vírus entéricos em amostras de esgoto, foram analisadas previamente três metodologias de concentração: i) floculação com extrato de carne, ii) eluição e floculação com proteínas de leite (skimmed milk) e iii) concentração baseada no uso de celite (terra diatomácea), seguindo protocolos previamente descritos: USEPA ${ }^{19}$; Calgua et al. ${ }^{20}$; Brinkman et al. ${ }^{14}$, respectivamente. O método de detecção utilizando celite foi o que apresentou os melhores resultados iniciais de recuperação para o bacteriófago PP7 e rotavírus ${ }^{21}$, sendo, desta forma, este procedimento escolhido para ser utilizado nos ensaios posteriores.

O bacteriófago PP7 usado como um controle interno dos experimentos para evitar a obtenção de resultados falso-negativos foi detectado em 85,4\% (41/48) das amostras de esgoto bruto analisadas, enquanto para efluentes secundários e água de reuso as taxas de detecção foram de 95,8\% (46/48) e 100\% (45/45), respectivamente, com eficiências médias de recuperação de 28 a 30\% em esgoto bruto, de 34 a $62 \%$ em efluentes secundários e de 26 a 59\% em água de reúso, como previamente publicado ${ }^{12}$.

De acordo com os dados, as amostras de esgoto bruto apresentaram maiores níveis de inibição em relação aos efluentes secundários e água de reuso, possivelmente devido à maior presença de sólidos totais e em suspensão, além de compostos inibidores, como ácidos húmicos, fúlvicos, metais pesados, entre outros, que podem comprometer os procedimentos de concentração, que incluem passos de filtração. A detecção viral também pode ser prejudicada pelo comprometimento da ação da enzima Taq DNA Polimerase nas reações de amplificação. Mesmo assim, as taxas de recuperação obtidas nas respectivas amostras ambientais foram consideradas desejáveis para detecção viral e próximas a taxas já observadas em outros estudos ${ }^{14,15,16,20}$.

Entretanto, de acordo com os resultados do monitoramento realizado durante um ano em águas residuárias e de reuso na cidade de São Paulo, os genomas do vírus da hepatite $\mathrm{E}$ não foram detectados durante todo o programa de monitoramento.

Os limites de detecção das análises de qPCR foram de $6,4 \times 10^{2}, 3,2 \times 10^{2} \mathrm{e}$ $80 \mathrm{CG} / \mathrm{mL}^{-1}$ para as amostras de esgoto bruto, efluentes secundários e água de reúso, respectivamente, e estão próximos a limites de detecção já reportados em outros experimentos utilizando metodologias similares para detecção de HEV RNA em amostras de soro 22 .

$\mathrm{Na}$ ausência de surtos, a detecção de vírus que não são endêmicos na população pode ser uma tarefa difícil em águas residuárias municipais, sobretudo devido à grande dispersão de vírus em grandes volumes de água. 
O limite de detecção dos métodos moleculares comumente adotados, especialmente aqueles baseados na amplificação de ácidos nucléicos, é relativamente elevado devido a uma série de passos requeridos para a análise, onde somente uma pequena fração do volume inicial da amostra é usado na reação de qPCR. Por esse motivo, cargas virais abaixo do limite de detecção dos métodos poderiam estar circulando e serem subestimadas em alguns estudos. Seria necessário aperfeiçoar os métodos de detecção moleculares, reduzindo seus limites de detecção, principalmente para aplicação em áreas não endêmicas ou de baixo risco para ocorrência de infecções por vírus da hepatite $\mathrm{E}$.

Entretanto, não se pode descartar a hipótese de que os resultados do estudo também sugerem baixas taxas e cargas de vírus da hepatite $\mathrm{E}$ circulantes na população servida pelos sistemas de esgotamento, desde que altas taxas de detecção e cargas virais foram obtidas para outros grupos virais entéricos, a exemplo dos norovírus, amplamente disseminados nessas mesmas matrizes ambientais e diagnosticados utilizando metodologias similares ${ }^{12}$.

Revisões recentes determinaram que as taxas de soro-prevalência de anticorpos anti-HEV no Brasil são de $6 \%$ entre a população adulta e de $3 \%$ na população geral, demonstrando que, embora não sejam taxas muito elevadas, a hepatite $E$ no Brasil não é rara ${ }^{23}$. Mas, deve-se destacar que as taxas de soroprevalência são distintas entre diversas regiões do país, sobretudo levando-se em consideração diferentes padrões de desenvolvimento sócio-econômico, além de acesso a serviços básicos de saúde e saneamento ${ }^{24,25}$.

Curiosamente, um estudo de revisão sistemática e meta-análise revelaram que o risco de exposição ao vírus da hepatite E é menor no Brasil quando comparado a outros países com maiores níveis de desenvolvimento sócioeconômico, como alguns países europeus e os Estados Unidos, demonstrado que níveis de renda e padrões sanitários não são os únicos fatores para explicar níveis endêmicos na população ${ }^{9}$.

Com base na assertiva anterior, um estudo recente realizado na cidade de São Paulo demonstrou uma maior prevalência de anti-HEV IgG $(9,8 \%)$ em um grupo de doadores de sangue representativos da população geral ${ }^{26}$. Taxas de soroprevalência apresentaram aumento cumulativo com a idade e variaram significativamente entre as zonas demográficas, com taxas mais altas nas zonas central e central-sul, as quais apresentavam relativamente maiores níveis de renda. ${ }^{26}$ Os autores sugeriram que os hábitos de alimentação (sobretudo ingestão de carne suína crua ou mal cozida) poderiam ter um papel significativo na transmissão de HEV na cidade de São Paulo ${ }^{26}$.

Além dos hábitos de alimentação específicas, como ingestão de carne de porco crua ou mal cozida, não se pode descartar que padrões de migração populacionais, contato direto com animais infectados, uso de drogas, entre outros, também poderiam contribuir para elevar as taxas de infecções em determinadas regiões 1,2,3,6,7,23,27. $^{1}$. 
Também deve-se levar em conta que pacientes com doenças pré-existentes, com órgãos transplantados e imunodeprimidos estão entre a população de risco para infecções por HEV, sobretudo risco para desenvolvimento de quadros crônicos da doença 28,29 .

Entretanto, qual seria a pertinência e a importância de cada fator - hábitos culturais, de alimentação, níveis sócio-econômicos, acesso a serviços básicos de saúde e saneamento, estado imunológico de pacientes, comportamentos de risco, como uso de drogas, entre outros - para traçar um perfil epidemiológico da doença no contexto da cidade de São Paulo, cujo número de habitantes é imenso e onde a heterogeneidade cultural, socioeconômica e espacial é tão marcante? Permanece a questão.

Além disso, deve-se enfatizar que poucos laboratórios no Brasil realizam testes anti-HEV e a doença não é de notificação compulsória, de modo que não temos dados suficientes nos sistemas de informação em saúde. Também a epidemiologia geral do vírus ainda é pouco compreendida no país, além da ausência de informações mais abrangentes sobre a ocorrência ambiental dos vírus, mecanismos de transporte em ecossistemas aquáticos, reservatórios e riscos de transmissão através da água e alimentos contaminados, havendo a necessidade, portanto, de mais estudos nesse tema.

\section{CONCLUSÃO}

Embora o HEV não tenha sido detectado nas matrizes ambientais pesquisadas, esta foi a primeira iniciativa para obter dados do vírus da hepatite $\mathrm{E}$ em amostras de água e esgoto na região metropolitana de São Paulo. Espera-se que futuros estudos de vigilância ambiental sejam conduzidos para ampliar a compreensão da epidemiologia do vírus e seu impacto ao ambiente e à saúde pública em diferentes regiões do país.

Financiamento: Este trabalho foi apoiado pela Fundação de Amparo à Pesquisa do Estado de São Paulo - FAPESP [número do processo: 2013/26586-1]

\section{AGRADECIMENTOS}

Gostaríamos de agradecer os funcionários da Companhia Ambiental do Estado de São Paulo - CETESB, especialmente Carlos Jesus Brandão, Vivian Baltazar Rocha, Marcelo Oliveira, Fernando de Caires e Waldemar Rodrigues por conduzirem as amostragens e análises de campo. Gostaríamos também de expressar nossa gratidão à Vilma Marques Santos Bonanno (in memoriam), 
virologista da CETESB, pela assistência durante o projeto e processamento de amostras.

\section{REFERÊNCIAS}

1. Melgaço JG, Gardinali NR, De Mello VDM, Leal M, Lewis-Ximenes LL, Pinto MA. Hepatitis E: update on prevention and control. Biomed Res Int 2018; Jan 9: 2018:5769201.

2. Pisano MB, Martinez-Wassaf MG, Mirazo S, Fantilli A, Arbiza J, Debes JD, et al. Hepatitis E virus in South America: the current scenario. Liver Int 2018; 38(9):1536-46. doi: 10.1111/liv.13881.

3. Organização Mundial da Saúde. Waterborne outbreaks of hepatitis E: recognition, investigation and control. (OMS. Informes Técnicos). Geneva: WHO; 2014. Disponível em:

http://apps.who.int/iris/bitstream/10665/129448/1/9789241507608_eng.pdf?ua=1 $\& u a=1$

4. Van Der Poel W, Rzezutka A. Hepatitis E. In: J.B. Rose and B. Jiménez-Cisneros, (eds) Global Water Pathogen Project. http://www.waterpathogens.org (J.S Meschke, and R. Girones (eds) Part 3 Viruses)

http://www.waterpathogens.org/book/hepatitis-e Michigan State University, E. Lansing, MI: UNESCO; 2017.

5. Secretaria Municipal de Saúde - SMS. Riscos e cuidados com a saúde após enchentes. Prefeitura de São Paulo, Coordenadoria de Vigilância em Saúde COVISA. Informe Técnico 005/DVE/2019. Disponível em: https://www.prefeitura.sp.gov.br/cidade/secretarias/upload/informe_tecnico_05_2 019_enchentes.pdf (último acesso: 01/04/2019).

6. Khuroo MS, Khuroo MS, Khuroo NS. Transmission of hepatitis E virus in developing countries. Viruses 2016; 8: 253 piiE253. doi:10.3390/v8090253

7. Oliveira-Filho EF, Lopes KGS, Cunha DS, Silva VS, Barbosa CN, Brandespim DF, et al. Risk analysis and occurrence of hepatitis $E$ virus (HEV) in domestic swine in northeast Brazil. Food Environ Virol 2017; 9(3):256-9. doi: 10.1007/s12560017-9292-6.

8. Souza WM, Romeiro MF, Sabino-Santos Jr G, Maia FGM, Fumagalli MJ, Modha $S$, et al. Novel orthohepeviruses in wild rodents from São Paulo State, Brazil. Virology 2018; 519:12-6. doi: 10.1016/j.virol.2018.03.025

9. Horvatits T, Ozga AK, Westhölter D, Hartl J, Manthey CF, Lütgehetmann M, et al. Hepatitis E seroprevalence in the Americas: a systematic review and metaanalysis. Liver Int 2018; 38(11):1951-64. doi: 10.1111/liv.13859. 
10. Amorim AR, Mendes GS, Pena GPA, Santos N. Hepatitis E virus infection of slaughtered healthy pigs in Brazil. Zoonoses Public Health 2018; 65(5):501-4. doi: $10.1111 /$ zph.12455

11. Heldt FH, Staggmeier R, Gularte JS, Demolier M, Henzel A, Spilki FR. Hepatitis E virus in surface water, sediments, and pork products marketed in Southern Brazil. Food Environ Virol 2016; 8(3):200-5.

12. Prado T, Bruni AC, Barbosa MRF, Garcia SC, Moreno LZ, Sato MIZ. Noroviruses in raw sewage, secondary effluents and reclaimed water produced by sandanthracite filters and membrane bioreactor/reverse osmosis system. Sci Total Environ 2019; 646: 427-37. doi: 10.1016/j.scitotenv.2018.07.301.

13. Prefeitura de São Paulo. Plano Municipal de Saneamento Básico de São Paulo. Volume 1 - texto. Disponível em: https://www.prefeitura.sp.gov.br/cidade/ secretarias/upload/habitacao/arquivos/PMSB_Volume_I.pdf. (último acesso em 01 abr. 2019).

14. Brinkman NE, Haffler TD, Cashdollar JL, Rhodes ER. Evaluation of methods using celite to concentrate norovirus, adenovirus and enterovirus from wastewater. J Virol Methods 2013; 193:140-6. doi: 10.1016/j.jviromet.2013.05.014.

15. Smith C.M, Hill VR. Dead-end-hollow-fiber ultrafiltration for recovery of diverse microbes from water. Appl Environ Microbiol 2009; 75(16):5284-89. doi: 10.1128/AEM.00456-09.

16. Rajal VB, Mcswain BS, Thompson DE, Leutenegger CM, Kildare BJ, Wuertz S. Validation of hollow fiber ultrafiltration and real-time PCR using bacteriophage PP7 as surrogate for the quantification of viruses from water samples. Water Res 2007; 41:1411-22.

17. Fumian TM, Leite JPG, Castello AA, Gaggero A, de Caillou MSL, Miagostovich MP. Detection of rotavirus $A$ in sewage samples using multiplex qPCR and an evaluation of the ultracentrifugation and adsorption-elution methods for virus concentration. J Virol Methods 2010; 170:42-6. doi: 10.1016/j.jviromet.2010.08.017.

18. Jothikumar N, Cromeans TI, Robertson BH, Meng XJ, Hill VR. A broadly reactive one-step real-time RT-PCR assay for rapid and sensitive detection of hepatitis $E$ virus. J Virol Methods 2006; 131:65-71.

19. Agência de Proteção Ambiental do Estados Unidos - USEPA, United States Environmental Protection Agency. Preliminary comparative study of methods to extract virus from raw and processed sewage sludge. EPA/600/R-07/118; 2007.

20. Calgua B, Rodriguez-Manzano J, Hundesa A, Calvo ESM, Bofill-Mas S, Girones R. New methods for the concentration of viruses from urban sewage using quantitative PCR. J Virol Methods 2013; 187:215-21. 
21. Prado T. Vírus entéricos emergentes em águas residuárias da cidade de São Paulo: epidemiologia e controle ambiental. São Paulo (SP): Companhia Ambiental do Estado de São Paulo (CETESB) / Fundação de Amparo à Pesquisa do Estado de São Paulo (FAPESP); 2017. Relatório Número: 2013/26586-1.

22. Salvio AL, Lopes AO, Almeida AJ, Gardinali NR, Lima LRP, de Oliveira JM, et al. Detection and quantification of hepatitis $E$ virus in the absence of IgG and IgM anti-HEV in HIV-positive patients. J Appl Microbiol 2018; 125(4):1208-15. doi:10.1111/jam.14024

23. Tengan FM, Figueiredo GM, Nunes AKS, Manchiero C, Dantas BP, Magri MC, et al. Seroprevalence of hepatitis $E$ in adults in Brazil: a systematic review and meta-analysis. Infect Dis Poverty 2019; 8(1):3. doi: 10.1186/s40249-018-0514-4.

24. Vitral CL, da Silva-Nunes M, Pinto MA, de Oliveira JM, Gaspar AM, Pereira RC, et al. Hepatitis $A$ and $E$ seroprevalence and associated risk factors: a communitybased cross-sectional survey in rural Amazonia. BMC Infect Dis 2014; 23(14):458. doi: 10.1186/1471-2334-14-458.

25. Bezerra LA, de Oliveira-Filho EF, Silva JVJ Jr, Santos Morais VM, Gonçales JP, da Silva D, et al. Risk analysis and seroprevalence of HEV in people living with HIVIAIDS in Brazil. Acta Trop 2019; 189:65-8. doi:

10.1016/j.actatropica.2018.09.026

26. Passos-Castilho AM, Reinaldo MR, De Sena A, Granato CFH. High prevalence of hepatitis $E$ virus antibodies in São Paulo, Southeastern Brazil: analysis of a group of blood donors representative of the general population. Braz J Infect Dis 2017; 21(5):535-9. doi: http://dx.doi.org/10.1016/j.bjid.2017.05.004

27. Castro VOL, Tejada-Strop A, Weis SMS, Stábile AC, de Oliveira SMVL, Teles $S A$, et al. Evidence of hepatitis $E$ virus infections among persons who use crack cocaine from the Midwest region of Brazil. J Med Virol 2019; 91(1):151-4. doi: 10.1002/jmv.25288.

28. Hering T, Passo AM, Perez RM, Bilar J, Fragano D, Granato C, et al. Past and current hepatitis E virus infection in renal transplant patients. J Med Virol 2014; 86(6):948-53. doi: 10.1002/jmv.23915.

29. Passos-Castilho AM, Porta G, Miura IK, Pugliese RPS, Danesi VLB, Porta A, et al. Chronic hepatitis $E$ virus infection in a pediatric female liver transplant recipient. J Clin Microbiol 2014; 52(12):4425-27.

Artigo recebido em: 11/03/2019

Artigo aprovado em: 03/04/2019

Artigo publicado em: 22/04/2019 